\title{
AESTHETIC MANAGEMENT OF FRACTURED ENDODONTICALLY TREATED TOOTH- CASE REPORT
}

\author{
Hada Singh Yajuvender, Suvil Wilson, Preeti Rajawat, Sonia Mathew, Disha Gupta
}

1. Reader, Department of Conservative and Endodontics, Daswani Dental College and Research Centre, KOTA.

2. Senior Lecturer, Department of Orthodontics, Daswani Dental College and Research Centre, KOTA.

3. Private Practitioner, Daswani Dental College and Research Centre, KOTA.

4. Tutor, Department of Conservative and Endodontics, Daswani Dental College and Research Centre, KOTA.

5. Tutor, Department of Conservative and Endodontics, Daswani Dental College and Research Centre, KOTA.

\author{
CORRESPONDING ADDRESS: \\ Dr. Hada Singh Yajuvender, \\ Reader, Department of Conservative and Endodontics, \\ Daswani Dental College and Research Centre, \\ Kota, Rajasthan \\ E-Mail: coolhadays@rediffmail.com, \\ Phone: 00919887733541.
}

ABSTRACT: Title - Aesthetic management of fractured endodontically treated teeth- Case report Healthy oral cavity is primary requisite for beautiful looks. Aesthetic requirement of severely mutilated teeth has been a challenge to dentist. This paper presents endodontic treatment of grossly decayed tooth followed by the placement of a fibre-reinforced composite resin post. The crown reconstruction was done with full ceramic crown. Resin fibre post has best properties in elasticity, translucency, adaptability and resistance to traction.

KEYWORDS: Aesthetic restoration, Post and core, Fibre resin post.

INTRODUCTION: Endodontically treated teeth are more prone to fractures than the vital teeth. Fracture occurrence is more in posterior teeth than anterior teeth as the masticatory forces are higher and teeth are weaker ${ }^{1}$. In cases where the teeth are severely decayed, endodontic treatment and placement of intracanal post or retainers become necessary before crown restoration. Posts maybe constructed of various materials including resins, composites, metals and biologic materials ${ }^{2}$. Recent years various types of fibre reinforcement have come into wide spread use as an alternative to cast or prefabricated metal posts in a restoration of endodontically treated teeth ${ }^{3}$. The advantages of using fibre post to construct an intracanal post include resin composite crown reinforcement, translucency, and relative ease of manipulation 4 . A post and core is a dental restoration used to sufficiently build up tooth structure for further restoration with a crown when there is not enough tooth structure to properly retain the crown due to loss of tooth structure to either decay or fracture. An anchor placed in the tooth root following a root canal to strengthen the tooth and help hold a crown in place ${ }^{5}$.

CASE REPORT: A male patient aged 48 years reported to the Department of Conservative and Endodontics with fractured mandibular left first premolar tooth for which root canal was done one year back without post endodontic restoration. The treatment plan was divided into two steps;

Step 1:- Clinical Examination: 


\section{CASE REPORT}

Crown fracture was seen with 34(Fig1). IOPA were taken in relation to 34. On radiographic examination the obturation was found to be intact and as the tooth was asymptomatic.

Step 2:- Construction of Restoration

On the basis of clinical and radiographic findings following treatment plan was made, restoration of the tooth with pre fabricated post, core build up and a porcelain jacket crown. For Post space preparation $4 \mathrm{~mm}$ of guttapercha was removed from the pulp chamber using a thin straight fissure bur. Post space was prepared with size no.2 piezo reamer supplied by manufacturer. FRC post of sizes number 2 with its diameter 1.06 was selected. The prepared space was cleaned with normal saline, air dried and bond non rinse conditioner was applied with help of an applicator tip for 20 seconds. After that two drops of each bond adhesive A and adhesive B (TANEX- fibre trans esthetic post system, Coltene Whaledent) were mixed in dispenser with help of applicator tip.It was uniformly applied in the prepared post space. It was then light cured for 20 seconds. Dual cure flowable composite resin cement (Para Core, Coltene Whaledent) was inserted into the post space after which the fibre post was inserted (Fig2). The fibre post and composite were cured together for 60 seconds. The excess coronal portion of the fibre post was cut with the help of a diamond bur. Final finishing and polishing was done with finishing burs and crown preparation for porcelain jacket crown was done. The crown was finally cemented with tooth using GIC luting cement (Fig3).

DISCUSSION: Teeth that have been endodontically treated often have little coronal tooth tissue remaining and as such require a post to retain the core and restoration. It was thought that the dentin in endodontically treated was more brittle because of water loss $^{6}$ and loss of collagen cross linking ${ }^{7}$. Huang et al. ${ }^{8}$ compared the physical and mechanical properties of dentin specimens from teeth with and without endodontic treatment at different levels of hydration. They concluded that neither dehydration nor endodontic treatment caused degradation of the physical or mechanical properties of dentin. These and other studies support the interpretation that it is the loss of structural integrity associate with access preparation, that lead to a higher occurrence of fractures in endodontically treated teeth compared with "vital" teeth". Access preparation results in increased cuspal deflection during function ${ }^{10}$ and increase the possibility of cusp fracture and micro leakage at the margins of restoration. Currently composite resin is most popular core material and has characteristics of an ideal buildup material. It has high tensile strength and the tooth can be prepared for a crown immediately after polymerization. Some authors showed that composite cores have fracture resistance comparable to amalgam and cast posts and cores ${ }^{11}$. It is tooth colored and can be used under translucent restorations without affecting the esthetic results.

CONCLUSION: Aesthetic requirement of severely mutilated teeth has always been a challenge for a dentist. If certain basic principles are followed in restoration of endodontically treated teeth, it is possible to achieve high levels of clinical success with. Therefore, restoration of teeth after endodontic treatment is becoming an integral part of restorative dentistry. The treatment described in case report is simple and effective and represents a promising alternative for rehabilitation of grossly destructed or fractured teeth.

\section{REFERENCES:}


1. Tang $\mathrm{W}, \mathrm{Wu} 1$, Smales RJ. Identifing and reducing risks of potential fracture in endodontically treated teeth. J Endod.2010; 36(vol 4):609-617.

2. Sholapurmath S.M. and Anand S. Use of polyethylene fibre in pediatric esthetics clinical reports of 2 cases. Journal of international oral health, 2010; vol2 no 2: 99.

3. Rachel De Oliveira Rocha, Lucimara Teixeira Das Neves, Noely Regina Marotti, Marcia Turolla Wanderley, Maria Salete Nahás Pires Corrêa. Intracanal reinforcement fibre in pediatric dentistry- case report. Quintenssence International. 2004 Vol 35: 263-268.

4. Vitale MC, Caprioglio C, Martignone A, Marchesi U, Botticelli AR. Combined technique with polyethylene fibres and composite resins in restoration of traumatized anterior teeth. Dental Traumatology 2004; vol 20: 172-177.

5. LeenaVerma and Sidhi Passi. Glass fibre- reinforced composite post and core used in decayed primary anterior teeth: case report. Case reports in dentistry 2011.

6. Helfer AR, Melnick S, Schilder H. Determination of moisture content of vital and pulpless teeth. Oral Surg Oral Med Oral Pathol 1972; 34: 661-70.

7. Rivera EM. Yamauchi M. Site comparison of dentine collagen crosslinks from extracted human teeth. Arch Oral Biol 1993;38:541-6.

8. Huang TJ, Schilder H,Nathanson D. effect of moisture content and endodontic treatment on some mechanical properties of human dentin. J Endodon 1991;18:209-15.

9. Reeh ES. Reduction in tooth stiffness as a result of endodontic restorative procedures. J Endodon 1989;15:512-6.

10. Panitvisai P, Messer HH. Cuspal defalcation in molars in relation to endodontic restorative procedures. J Endodon1995;21:57-61

11. Pilo R, Cardash HS Levin E, Assif D. effect of core stiffness on the in vitro fracture of crowned, endodontically treated teeth. J Prosthet Dent 2002;88:302-6.

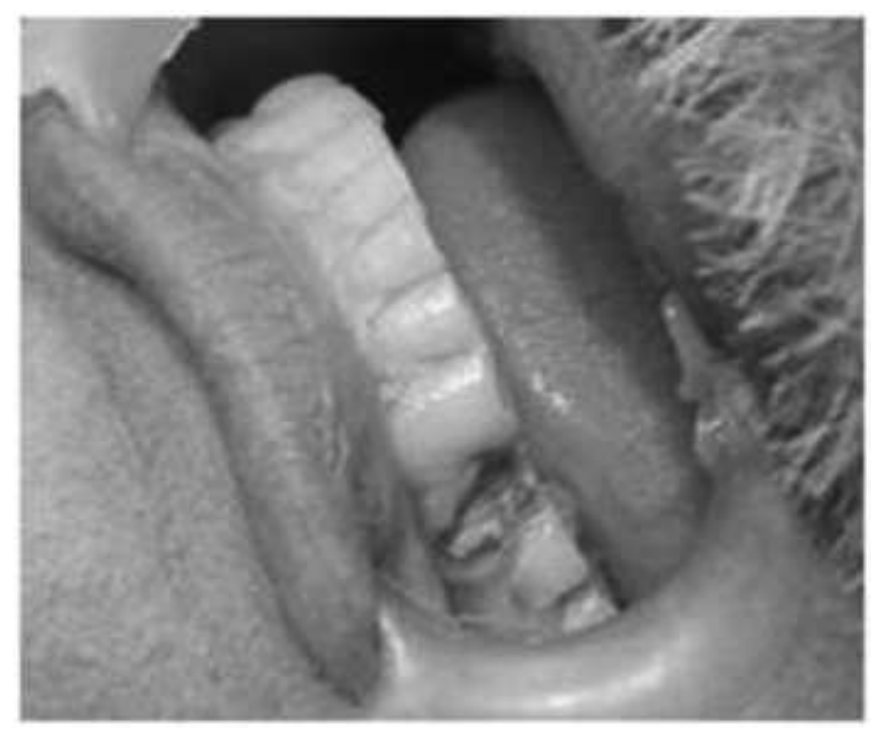

Figure 1: Crown fracture of 34, 


\section{CASE REPORT}

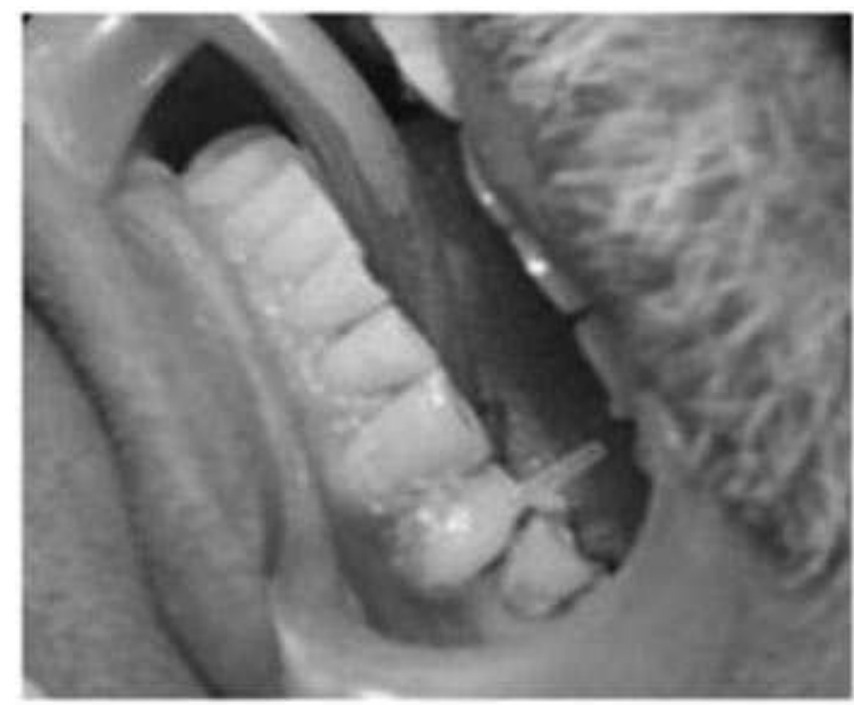

Figure 2: Fibre post and composite were cured,

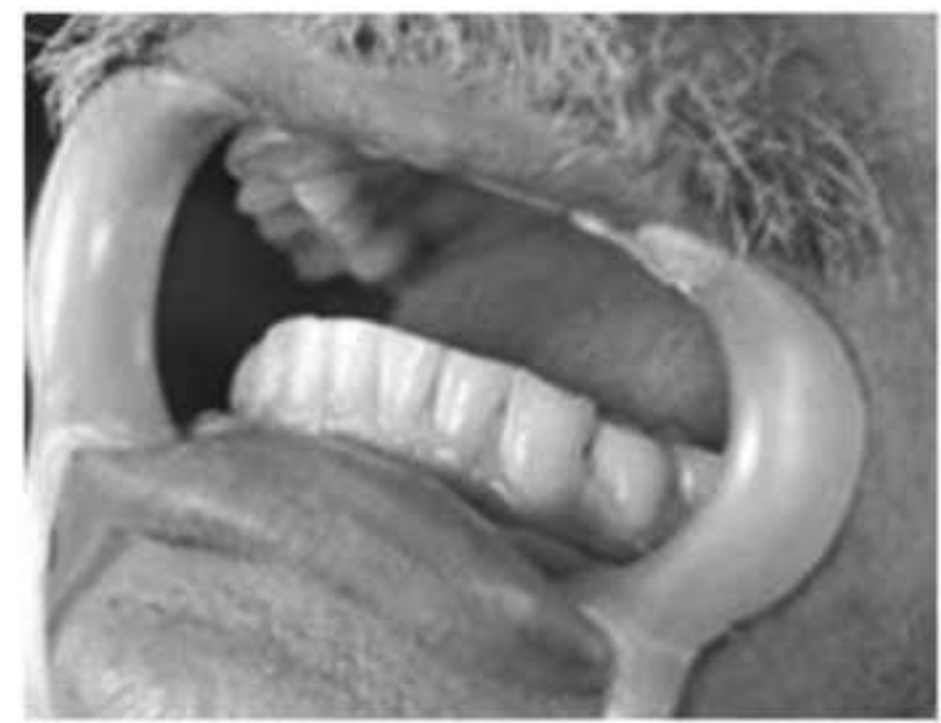

Figure 3: Porcelain jacket crown cemented on 34 